\title{
Hambre y soberanía alimentaria entre los kaiowa y guaraní en el Brasil ${ }^{1}$
}

\section{Nádia Heusi Silveira}

(D) https://orcid.org/0000-0003-1484-6851

Instituto Nacional de Ciencia y Tecnología Brasil Plural

nheusi@yahoo.com.br

\section{RESUMEN}

A lo largo de los últimos setenta años, los kaiowa y guaraní que viven en Brasil sufrieron la pérdida masiva de sus territorios tradicionales. A partir del caso de Tierra Indigena Caarapó se argumenta que la expropiación territorial y las políticas públicas que la promovieron condujeron a cambios sociales y ambientales significativos y disgregadores entre los kaiowa y los guarani, comprometiendo su soberanía alimentaria. Se muestra que los rituales - no se realizan más - ligados a la producción agrícola eran eventos que producían reciprocidad ampliada entre las parentelas, además de la abundancia de alimentos. Se concluye que el enfrentamiento de la situación por el Estado, en lo que se refiere a la garantía de la seguridad alimentaria y nutricional de estos pueblos, ha sido parcial y desalentador.

Palabras clave: soberanía alimentaria, rituales del maíz, territorio tradicional, inseguridad alimentaria, kaiowa y guaraní.

\footnotetext{
1 Agradezco mucho a Nora Murillo Estrada por la traducción al español de este artículo, como también por sus sugerencias a partir de la versión en portugués.
} 


\title{
Fome e soberania alimentar entre os Kaiowa e Guarani no Brasil
}

\author{
RESUMO
}

Ao longo dos últimos 70 anos, os Kaiowa e Guarani que vivem no Brasil sofreram a perda massiva de seus territórios tradicionais. Tomando a situação da Terra Indígena Caarapó, argumenta-se que a expropriação territorial e as políticas públicas que a promoveram conduziram a mudanças sociais e ambientais significativas e desagregadoras, as quais comprometeram a soberania alimentar entre os Kaiowa e Guarani. Mostra-se que os rituais não mais realizados, ligados à produção agrícola, eram eventos que produziam a reciprocidade ampliada entre as parentelas, além da fartura de alimentos. Conclui-se que o enfrentamento da situação por parte do Estado, no que diz respeito à garantia da segurança alimentar e nutricional destes povos, tem sido parcial e pouco promissor.

Palavras-chave: soberania alimentar, rituais do milho, território tradicional, insegurança alimentar, kaiowa e guarani.

\section{Hunger and Food Sovereignty among the Kaiowa and Guaraní in Brazil}

\section{ABSTRACT}

Over the last 70 years, the Kaiowa and Guarani peoples living in Brazil have suffered massive loss of their traditional territories. Examining the case of the Caarapó Indigenous Land, the article argues that territorial expropriation, along with the public policies that promoted it, led to significant and disruptive social and environmental changes for the Kaiowa and Guarani and has compromised their food sovereignty. It demonstrates that the rituals of the past related to agricultural production were events that produced extended reciprocity between kin groups and abundance of food for all. It is concluded that the State's actions taken to resolve the current situation and to guarantee food and nutritional security of these peoples, have been partial and disappointing.

Keywords: food sovereignty, maize rituals, traditional territory, food insecurity, Kaiowa and Guarani. 


\section{INTRODUCCIÓN}

Hace más de cien años, en 1915, fue demarcada por el Estado brasileño la primera área reservada a los kaiowa y guaraní en el centro-oeste del país: el Puesto Indígena Benjamin Constant, en el municipio de Amambai. Desde entonces, el modo de vida de los kaiowa y guaraní sufrió grandes transformaciones asociadas a un proceso de expropiación territorial para la expansión de la frontera agrícola en la región del centro-oeste brasileño. Este hecho histórico está bien documentado y analizado por Brand (1997), Pereira (2004), Vietta (2007) y Cavalcante (2013), entre otros autores.

De acuerdo con Brand (1997), los primeros frentes colonizadoras a disputar los territorios de los kaiowa y guaraní se remontan a finales del siglo XIX. Sin embargo, para este historiador, la situación actual tiene su marco en la década de 1940, con la implementación de políticas de Estado para estimular la migración y sujeción de productores rurales en la región.

Especialmente en las décadas de 1950 y 1960, debido a la creciente explotación de los campos naturales para la producción de ganado, se intensificó el esfuerzo paralelo del órgano indigenista estatal para liberar las tierras habitadas por los kaiowa y guaraní - las zonas forestales - y se los reubicó en reservas indígenas ${ }^{2}$ ya existentes. Con la premisa de que esos pueblos serían paulatinamente

2 Entre 1915 y 1928, fueron creadas ocho reservas indígenas en la región que hoy corresponde al estado de Mato Grosso do Sul, de menos de 18000 hectáreas, para usufructo de todos los kaiowa y guaraní que vivían en el país. Son: Dourados, Amambai, Caarapó, Limão Verde, Taquapiry, Pirajuy, Porto Lindo y Sassoró. La institucionalización de reservas correspondió a las primeras iniciativas de «protección» de los indios en el Brasil y fue ejecutada por un órgano federal creado en 1910: el Servicio de Protección a los Indios (SPI). Sin embargo, debido a una serie de irregularidades y denuncias de corrupción, el órgano fue extinguido a mediados de la década 1960. Luego se creó la Fundación Nacional del Indio (FUNAI), institución gubernamental federal responsable de las políticas indigenistas hasta el presente. Vale notar que los principios del indigenismo de Estado pasaron por modificaciones significativas 
asimilados a la sociedad nacional como trabajadores civiles, su organización social no constituía un problema (Brand, 2010). Los kaiowa y guaraní, en general, no tenían otra alternativa que ceder sus tierras a los productores rurales recién llegados de otras zonas del país e ir a las reservas determinadas por los agentes del Estado. Así, parentelas ${ }^{3}$ que difícilmente vivieron en un mismo lugar por iniciativa propia pasaron a convivir (Thomaz de Almeida, 2001). No fue un proceso pasivo para los kaiowa y guaraní, pero las estrategias coercitivas e incluso violentas empleadas tanto por los terratenientes como por la organización indigenista no permitieron mucha variación en ese proceso obligatorio de reterritorialización (Barbosa da Silva, 2012).

En el principio de ese proceso, fue posible que algunas parentelas permanecieran en los remanentes de los bosques, viviendo dentro de las propiedades como mano de obra explotada por los hacendados, según Brand (1997) y Thomaz de Almeida (2001). Todavía, con el estímulo de la soyacultura en la década de 1970, la cubierta vegetal existente fue reemplazada por la siembra de soya, además de la siembra de caña de azúcar en la década de 1980 (Lima y Guimarães, 2013). Hoy los territorios tradicionales de los kaiowa y guaraní, constituidos por suelos fértiles, soportan una producción agrícola de gran escala, para exportación.

En este artículo, examino la situación de inseguridad alimentaria de los kaiowa y guaraní en Mato Grosso do Sul, tomando en cuenta el curso de los cambios históricos anotados antes, que impactan la vida de estos pueblos. Tomaré como caso de análisis la Tierra Indígena Caarapó, para dar cuenta de las transformaciones en las prácticas implícitas en la producción alimentaria, particularmente desde la economía y el chamanismo, con el propósito de demostrar en qué sentido la soberanía alimentaria es un concepto que tensiona las políticas públicas de seguridad alimentaria para los pueblos indígenas.

Desde una perspectiva etnográfica, este análisis difiere de la tendencia teórica de los estudios de etnología indígena, cuyo supuesto es abordar las transformaciones históricas como continuidad en términos culturales (ver Fausto y Heckenberger, 2007). La intención de señalar la pérdida del poder de lo que se define como soberanía alimentaria trae la idea subyacente de discontinuidades

después de la promulgación de la Constitución Federal de 1988 y, en 2008, la propia FUNAI inició una reestructuración interna alineada con los derechos garantizados a los indios, pero no se implementó completamente.

3 Es una categoría propuesta por Pereira (2004), derivada de la expresión kaiowa te'ýi, que expresa su organización sociopolítica desde el espacio compartido en la convivencia familiar. En español podría comprenderse como núcleos o unidades multifamiliares. 
que implican cruces entre las dimensiones ambiental, social, política, económica y chamánica, generadas por cambios históricos.

Soberanía alimentaria es un concepto que surge en debates internacionales, en 1996, difundido por la Vía Campesina, en torno de la dualidad entre los intereses del libre comercio, desde modelos agroexportadores neoliberales, $\mathrm{y}$, por otro lado, los intereses de los pequeños agricultores en mantener su autonomía productiva (Marques, 2010). En Brasil, desde 2006, la soberanía alimentaria es considerada un principio para acciones de seguridad alimentaria, con base en la Ley Orgánica de Seguridad Alimentaria y Nutricional (LOSAN), la cual normaliza las políticas de seguridad alimentaria y nutricional que vienen siendo implementadas desde entonces. En esta ley, la soberanía alimentaria se refiere a la supremacía del Estado sobre las decisiones sobre la producción y el consumo de alimentos por la población brasileña.

La definición utilizada en este estudio no incorpora la perspectiva estatal, pero abarca las diferencias culturales en la producción y consumo de alimentos conforme propone la Vía Campesina: «La soberanía alimentaria es el derecho de los pueblos a alimentos nutritivos y culturalmente adecuados, accesibles, producidos de forma sustentable y ecológica, y el derecho a decidir su propio sistema alimentario y productivo» (2007, citado por Xavier, 2018).

El estudio de campo en Caarapó ${ }^{4}$ se desarrolló entre los años 2004 y 2008, cuando integraba el Núcleo de Estudios e Investigaciones de las Poblaciones Indígenas de la Universidad Católica Don Bosco (NEPPI-UCDB). Fueron varias visitas cortas y sistemáticas en las que acompañé actividades en la escuela, en el puesto de salud y reuniones, además de las visitas domiciliarias en varios sectores de la división espacial interna de la aldea. Las observaciones, charlas informales y entrevistas realizadas a lo largo de ese período, como también contactos posteriores como agente de la FUNAI, en 2012 e 2013, constituyeron los datos que se entretejen en este artículo.

4 La investigación fue financiada con recursos obtenidos a través de la convocatoria MCTCNPq/MS-SCTIE-DECIT n ${ }^{\circ}$ 38/2005, y con una beca de estudios concedida por la Fundación de Apoyo al Desarrollo de la Enseñanza, Ciencia y Tecnología (FUNDECT) del estado de Mato Grosso do Sul, entre 2006 y 2008. Quiero agradecer aquí a Symonne Parizotto por la estimulante coordinación del proyecto, a Rosa Colman por la asistencia con las traducciones y también al equipo de agentes indígenas de salud que participó en la realización del estudio de campo. 
Antes que nada, me gustaría llamar la atención sobre dos aspectos. Primero, que está enfocada en una aldea de unos cincuenta asentamientos ${ }^{5}$ kaiowa y guaraní existentes en Mato Grosso do Sul. Hay marcadas diferencias entre los asentamientos por su contexto físico, ambiental y social; por ejemplo, lugares con más o menos bosques o diferenciaciones con relación a la situación jurídica sobre la tierra. Estos aspectos plantean diversas eventualidades y diferentes grados de inseguridad alimentaria en la población como un todo. Segundo, desde que se realizó esta investigación han ocurrido varios cambios, tanto en el ámbito de las políticas de protección social como en el cuadro político brasileño. Los datos presentados corresponden al inicio del gobierno del Partido de los Trabajadores en el Brasil. Posteriormente, otras acciones de seguridad alimentaria y nutricional fueron implementadas entre pueblos indígenas y, más recientemente, se observa un retraimiento de las políticas indigenistas. Precisamente por eso, divulgar estos datos parece oportuno.

\section{LOS KAIOWA Y GUARANÍ EN LA TIERRA INDÍGENA CAARAPÓ}

Los kaiowa y guaraní se identifican como agricultores. Estos pueblos habitan, en su mayoría, al sudoeste de Mato Grosso do Sul, en Brasil, y la región oriental de Paraguay. Los kaiowa son conocidos como tavyterã o pai-tavyterã en el Paraguay, y los guaraní son también conocidos y referidos en la literatura como ñandéva o $a v a^{6}$. En el Brasil, son la segunda mayor población indígena del país, con cerca de 45000 personas, y enfrentan, de forma cada vez más cruel, conflictos agrarios y violencia armada (Silveira, 2016).

5 Hablo de asentamientos por falta de otra expresión que designe la forma actual de ocupación de los territorios tradicionales, que abarcan tierras indígenas regularizadas, en proceso de regularización, todavía en fase de estudios técnicos, y muchas aldeas jurídicamente irregulares, conocidas como «campamentos» o «retomadas».

6 Los pueblos guaraníes son identificados por hablar la misma lengua. Los etnónimos que hoy en día adoptan en la relación con los no indios, en esta región, son kaiowa y guaraní. En el Brasil, todavía se considera la existencia de tres dialectos guaraní en el territorio nacional, equivalentes a las parcialidades kaiowa, ñandéva e mbya, según Schaden (1974), a pesar de los debates actuales que cuestionan esas clasificaciones. Los mbya no se encuentran en Mato Grosso do Sul: viven en la franja costera meridional junto con los ñandéva. 


\section{Mapa 1. Localización de la Tierra Indígena Caarapó en Mato Grosso do Sul (adaptado de NEPPI-UCDB)}

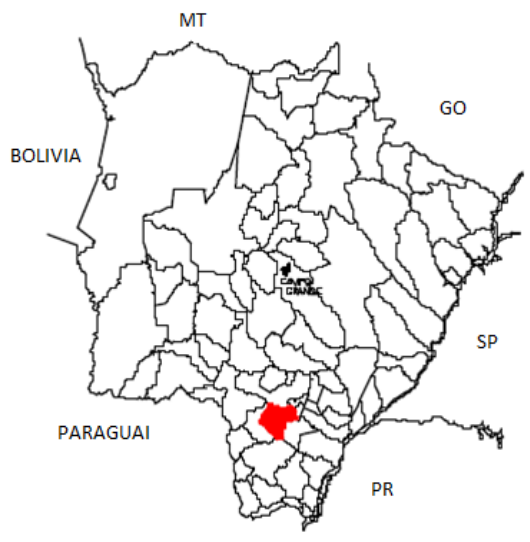

MATO GROSSO DO SUL

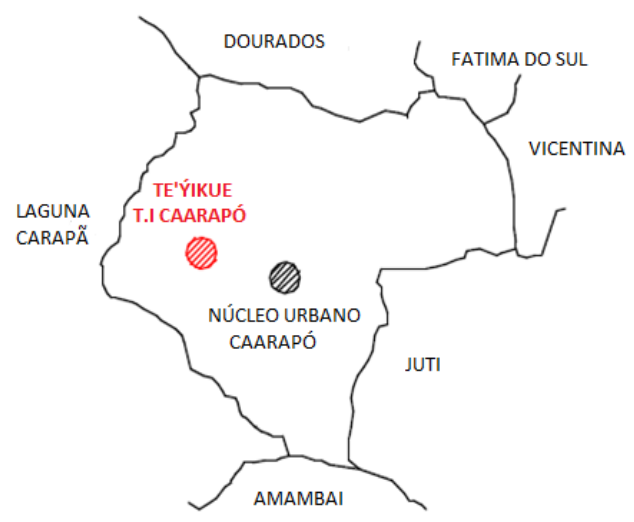

MUNICÍPIO DE CAARAPÓ

El municipio de Caarapó, donde se ubica la Tierra Indígena en la que se realizó la investigación de campo, tiene cerca de 26000 habitantes (Instituto Brasileiro de Geografia e Estatistica [IBGE] ${ }^{7}$, 2010). El poblado surgió en 1927, apenas después de tres años de ser reservada, para los kaiowa, un área de aproximadamente 3600 hectáreas, identificada en la época como Puesto Indígena José Bonifacio. Esa desocupación previa del espacio en que surge la ciudad representa el esfuerzo del Estado brasileño por liberar las tierras vacantes en las regiones que deberían ser pobladas y desarrolladas (Brand, 1997; Thomaz de Almeida, 2001). Hoy, grandes propiedades rurales bordean esta Tierra Indígena y existe una usina ${ }^{8}$ para la producción industrial de azúcar y etanol en Caarapó.

En el lugar en que fue instalado el Puesto Indígena, en 1924, ya vivían algunas parentelas kaiowa. De acuerdo con Cariaga (2011), había allí un tekoha9

Recuperado de http://www.ibge.gov.br/estadosat/perfil.php?sigla=ms\#

8 En otros países de América Latina, particularmente en Centroamérica, a estas plantas de procesamiento de caña de azúcar se les reconoce como «ingenios», distinguiéndolas así de otro tipo de plantas generadoras de energía, como las hidroeléctricas.

9 Entre los antropólogos existe una divergencia productiva sobre la noción de tekoha y su uso como categoría analítica en correspondencia al espacio geográfico (ver, por ejemplo, Thomaz de Almeida y Mura, 2004; Melià, Grünberg y Grünberg, 2008; Pereira, 2004). Considero tekoha un término polisémico que indica vínculos políticos, económicos y chamánicos entre las familias, pero también cierta cualidad del paisaje en que viven, asociado a los aspectos 
como llaman a los lugares que ocupan. Te'ýikue, esta ubicación, era una región de bosque denso según lo declarado por los ancianos que permanecen allí. Los kaiowa y guaraní, cuando se refieren a esta Tierra Indígena en portugués, dicen aldea Te 'ýikue, por eso menciono el lugar también como aldea a lo largo del texto.

Como las demás áreas reservadas para los kaiowa y guaraní en el inicio del siglo pasado, la Tierra Indígena Caarapó recibió muchos grupos de otros tekoha, como Takuara, Javevyry, Ypytã y Javorai (Benites y Colman, 2012), traídos por agentes del órgano estatal indigenista. Una mujer guaraní testificó que los agentes del SPI convencieron a sus parientes de mudarse diciéndoles que en la reserva había fábrica de rapadura, trabajo y mucha cosa buena. Ellos fueron llevados en camión, y al llegar descubrieron la mentira, pero ya no pudieron volver a su lugar de origen, porque les estaba prohibido. Además de estrategias convincentes como esta, también ocurrían acciones violentas.

Las parentelas guaraní que viven actualmente en Te'ýikue, como también algunas familias kaiowa, fueron desplazadas sin elección. En el final de la década de 1940, Schaden (1974) estimó que vivían en el lugar doscientos a trescientos kaiowa más unos pocos guaraní. Un número razonable de habitantes conforme las descripciones dadas por Noelli (1999) y Lehner (2002) al respecto de la población en los tekoha antes de la expansión agrícola en el centro-oeste. Según Cariaga (2011), los guaraní que iban llegando a Caarapó pasaron a habitar el mismo lugar dentro de la reserva. Actualmente, los kaiowa y guaraní reconocen catorce subregiones en su interior. Aproximadamente, en cada uno de esos espacios internos hay un liderazgo reconocido que congrega un grupo de parientes o una red de parentelas.

Actualmente, las parentelas (te' $y i$ ) siguen siendo un referente para la organización social en la aldea (Vietta, 2001; Pereira, 2010). Ellas se constituyen a partir de la unión de un número variable de fogones domésticos, con más o menos distancia social entre ellos, en torno de una pareja de esposos. Las parejas más ancianas encabezan su grupo de parientes por medio del prestigio político, asociado al conocimiento chamánico y también del mundo contemporáneo. Sin embargo, dados los reordenamientos sociopolíticos mencionados anteriormente, se observa una tendencia de retraimiento de reciprocidad entre los miembros de las parentelas.

físicos y a la existencia de entidades protectoras del ambiente y sus elementos (agua, árboles, fauna, etcétera), los jára, cualidad esta que puede ser potencializada por la acción chamánica. 
El fogón doméstico es su menor unidad sociológica según Pereira (2004), o, dicho de otra manera, su expresión familiar primaria, equivalente al vocablo kaiowa che ypyky kuera. Eso podría traducirse como «mis descendientes directos» y abarca un grupo de parientes corresidentes que comparten el fuego en el suelo, la comida y gran intimidad. Comúnmente, en ese fuego se incluyen parientes, además de la familia nuclear. La composición de los fogones domésticos, así como las articulaciones entre ellos, no son estables. En el caso de parentesco bilateral con tendencia a la endogamia, es común que el esposo y la esposa mantengan la convivencia estrecha con parientes consanguíneos y afines, lo que favorece reconfiguraciones en sus relaciones (Pereira, 2004).

Por otro lado, la lealtad política a la pareja que lidera una parentela supone algún grado de disputa con miembros de las demás parentelas. Asimismo, aunque algunos guaraní se hayan aliado a los kaiowa por casamiento y relaciones establecidas en la política interétnica, los kaiowa terminan sosteniendo ventajas sobre los recursos que llegan de organizaciones gubernamentales y no gubernamentales, pues habitaban en este lugar antes que los guaraní, que vivían más al sur del Estado. Estas ventajas marcan diferencias de los kaiowa con respecto a los guaraní.

En la actualidad, las disputas y rivalidades se traducen, a veces, en reacciones violentas y muertes. Las rencillas políticas, frecuentes en la Tierra Indígena Caarapó, están relacionadas no solo con la intensificación de disputas entre parentelas debido a la heterogeneidad social derivada de la reterritorialización, sino también con la densidad poblacional, el impedimento para circular en el territorio y un modelo de relaciones con los no indígenas inaugurado a partir de la estructuración de capitanías por el SPI (ver Silveira, 2016).

A lo largo de los noventa años en que la dinámica política kaiowa y guaraní fue adaptándose al modelo de capitanía en la aldea — esto es, la imposición de un liderazgo escogido y reconocido por agentes estatales para representar a la comunidad, modelo que tuvo variaciones importantes en el transcurso del tiempo-, los liderazgos tradicionales perdieron prestigio (Brand, 1997; Pereira, 2007; Vietta, 2003). Este hecho repercutió directamente en el olvido progresivo de eventos rituales y festivos en torno de la producción agrícola, como veremos más adelante. Sin embargo, la cooptación y empoderamiento de líderes para influir en decisiones sobre los procesos en las aldeas, sigue siendo la práctica de los agentes de los órganos de gobierno en instancias locales y nacionales, como también de entidades religiosas y no gubernamentales. 
El aumento de la densidad poblacional en esta Tierra Indígena en las últimas décadas es un factor clave para entender la recurrencia de agresiones fatales, pero es fundamental, sobre todo, para indicar la disminución de los recursos ambientales disponibles para cada fogón doméstico en términos cuantitativos. De pocas centenas de habitantes en la mitad del siglo pasado, la aldea pasó a abrigar a una población de cerca de 2000 personas a principios de siglo (Vietta, 2003). Datos más recientes estiman una población de 5200 personas (FUNAI, 2012). Tal concentración demográfica es superada apenas en las Tierras Indígenas Amambai y Dourados. En estas tres antiguas reservas indígenas vive hoy casi la mitad de toda la población kaiowa y guaraní de Mato Grosso do Sul.

En sus inicios, el área reservada en Caarapó tenía muchos árboles frutales, según relatan algunos moradores antiguos ${ }^{10}$. «Había guavira, pacuri, jatobá, pindó, macaúba, jaracatiá, araticum, goiaba, goiabinha, pitanga, guaimbé, jabuticaba y otros». Algunas de estas frutas, además de otras que crecían en la aldea, eran alimentos para los grandes animales de caza, como tapir, venado y puercos de monte, que se encontraban fácilmente en los alrededores. Otros tipos de árboles, como «tarumã, peroba y cañafístula», servían para obtener la miel, un alimento muy apreciado. En los relatos, hombres y mujeres kaiowa y guaraní se refieren a varios tipos de abejas de las cuales colectaban la miel: eirusu, jatei, eipytã, tapesu'a, mumbucão, mumbuquinha, arapuá. En el entorno también era posible la pesca, pues la aldea se encuentra en un área entre los ríos Ivinhema y Amambai y es abastecida por ramificaciones de estos ríos. En las primeras décadas después de la creación del Puesto Indígena José Bonifacio, era posible también cazar y pescar en los matorrales de lugares más distantes, fuera del área reservada.

Hoy las actividades de recolección se reducen prácticamente a lo que se planta alrededor de las casas. Caminar en busca de alimentos y otras materias primas para remedios y artefactos actualmente es poco fructífero en la Tierra Indígena Caarapó. Los hombres que consiguen cazar lo hacen con permiso de algún administrador de hacienda, en las pocas áreas de bosque preservadas en las tierras privatizadas circundantes. Pero difícilmente se encuentran los grandes animales de caza. En la propia aldea es posible cazar todavía algunas especies de armadillos, agutí, preas, aves y otros animales pequeños. La pesca es viable

10 Registro de transcripción de entrevista en la TI Caarapó, Teko Arandu, 2008. 
en algunas corrientes y lagos ${ }^{11}$ en el interior de la aldea y en las proximidades, pero hay poca cantidad de peces, según los kaiowa y guaraní.

A pesar de afirmarse agricultores, durante la investigación de campo observé que poquísimas familias conseguían mantener una chagra grande y variada. Ya no cultivan ciertos alimentos considerados tradicionales, como el mbakuku, un tubérculo del cual hablaban mucho por ser apreciado y también indicado como un alimento para estimular a las madres a tener leche. No escuché ninguna mención a trabajos colectivos en la chagra, una actividad festiva — además de productiva — en la que estaba implícita una invitación para comer y beber chicha con aquel que invitaba, como retratan etnografías más antiguas sobre los guaraní. Mis interlocutores principales eran los profesores y profesoras kaiowa y guaraní de la escuela de la aldea y las agentes indígenas de salud, en la media de veinte a treinta años de edad, y ellos tampoco recordaban sobre rituales y fiestas del maíz, realizados en la aldea.

En las entrevistas realizadas con moradores en la Tierra Indígena Caarapó fluyó gran nostalgia por la comida antigua. Los más ancianos se emocionan al hablar este tema. Y el presente es visto como una situación de penuria frente a un pasado de abundancia.

Antiguamente, los niños tomaban chicha, no tomaban leche. Comían harina de maíz blanco, hacía harina de maíz, comía armadillo, solo eso comía. Y armadillo, gallina, paca, mataba venado, lorito hacía con mbaipy [polenta de maíz], así comía cocido, yuca cocida para niños comer. Y también papaya, miel de jateí daba un poquito al niño pequeño. [...] La miel de abeja era llamada kaitykue. Endulzaba la chicha, y dava al niño, que tomaba, engordaba. No hacía mal. Hacía chicha de yuca que llamaba karaku. Hacían bastante chicha y después danzaban kotihu, guachiré, no tenían pelea ni desacuerdos (entrevista a Cristina Barbosa, 2008).

Comida de niño es canjica. Yuca asada y también cocida, banana cocida o asada, guaimbé asado, perera [harina de maíz]. Todo puede comer, como mbaipy [polenta de maíz], perera, y todo que es hecho de maíz el niño puede comer, xipa. El xipa de antiguamente hoy se llama de pan. El xipa es hecho con maíz, después de rallarlo se enrolla en el pariri [hoja lisa]. El maíz verde para salir el pan es colocado después de amarrado debajo de la ceniza. Eso que es llamado xipa tanimbuguy. Y cocido en el agua es lo que se llama tamal dulce de elote o xipa tumbykua. Para comer junto con este, mataba un animal del monte, como quati, tatu, cotia, paca, cateto, anta, capibara. Era con eso

11 Uno de los proyectos desarrollados por el NEPPI-UCDB fue la construcción de dos represas en la Tierra Indígena Caarapó. En las presas formadas, se colocaron crías de peces para crecer y servir como alternativa alimentaria. 
tratado el niño, rata que vive en la granja era asado, tiraba la tripa y asaba en el fuego. El ratoncito o armadillo era cocido o asado, todos los tipos de armadillo y tamanduazinho. Cuando las niñas eran pequeñas, mamando, no comía ese tipo de alimento (entrevista a Ari Vidal e Leónides Ricarte, 2008).

Entonces mi madre finada decía que antiguamente mi padre le contó que quien hacía xipa [pan de maíz] no era salado, no colocaba aceite. Cuando mataba armadillo o animal de monte no salaba el caldo. Cuando mataba anta, lo colocaba en la tarima, y después de sacarle la piel, lo colocaba allá y hacía fuego en leña [...]. Y después colocaba debajo de la ceniza enrollada la carne con la piel, en la ceniza como si fuera yuca asada que nosotros comíamos. Pero no se colocaba sal. Así que nosotros comíamos como antiguos. Incluso cuando traían el centro del árbol de coco que hoy se llama palmito, después de traerlo se cortaba en el tazón como si fueran fideos pequeños, hervidos, después cocinaban, hasta el caldo de palmito ellos tomaban. Igual que toma el caldo del animal de monte. Nosotros no necesitábamos de sal ni aceite, no conocíamos arroz, macarrón, ni jabón. Mi finada madre decía que antiguamente no se usaba jabón, pero sí el timbó. Cuando traía el timbó, lo descascaba, raspaba, después lo colocaba en el sol, se convertía en harina que ponía en el paño. Sacaba mucha espuma, con eso ellos lavaban sus ropas. Antiguo era así (entrevista a Tereza Martins, 2008).

De acuerdo con Meliá y otros (2008), cuando los kaiowa y guaraní poseían relativa autonomía económica, los alimentos cultivados correspondían a cerca del $80 \%$ de los alimentos consumidos. Sin embargo, a medida que la población crecía y los alrededores, así como la aldea misma, estaban siendo devastados y deforestados, las prácticas alimentarias cambiaron. Los relatos de hombres y mujeres en la media de sesenta a ochenta años de edad y los datos de las prácticas alimentarias actuales evidencian cambios significativos en términos de la incorporación de los alimentos procesados industrialmente y en la manera de preparar la comida, pues la leña es difícil conseguir en la aldea.

\section{AGRICULTURA, RITUALES Y CHAMANISMO}

El proceso de expropiación territorial, o confinamiento en las reservas indígenas y la precarización de la vida actual entre los kaiowa y guaraní se oponen radicalmente a la memoria de las fiestas y de un pasado abundante que todavía guardan los más ancianos. Como dije antes, hace décadas no ocurren grandes rituales encabezados por rezadores en la Tierra Indígena Caarapó. Incluso, en la época del estudio había muchas iglesias neopentecostales dispersas por la aldea, 
con un contingente significativo de convertidos ${ }^{12}$. Por eso, la descripción de los rituales se sustenta en la literatura. Mi interés es mostrar que el ciclo de rituales en torno a la agricultura delimitaba un calendario estacional, en que las prácticas agrícolas eran intensificadas y se constituían en modos de relación que propiciaban intercambios económicos ampliados.

La disertación sobre cantos chamánicos de Izaque João (2011), profesor kaiowa de la Tierra Indígena Panambi, es notable en su descripción de la imbricación entre las prácticas chamánicas, la relación con el ambiente físico y las relaciones sociales. Los rezadores con gran capacidad de visión sobre la realidad invisible ${ }^{13}$, reconocidos socialmente como tekoaruvixa, aglutinaban poder chamánico y político (Pereira, 2004; Vietta, 2007). Así, cuanto más plena la comunicación del rezador con las divinidades, mayor era el acceso del chamán a los niveles cósmicos o alumbramientos celestiales y, mayor número de parentelas reconocían su sabiduría y su liderazgo en el plano social, prestándole apoyo y solidaridad en las tareas que involucraban la producción de los rituales, lo que estimulaba la formación de alianzas entre grupos pertenecientes a diversos tekoha. Estos rezadores prestigiados también agregaban en torno de sí un buen número de yvyra'ija, jóvenes aprendices, a quienes transmitían conocimientos y rezos a lo largo de varios años, que en los rituales podrían actuar como sus auxiliares.

El chamanismo, practicado por hombres (ñanderu) y mujeres (ñandesy), se fundamenta en el canto-danza, jeroky o ñembo' e. Estos rezos, que pude presenciar varias veces, son cantos acompañados de movimientos como caminar en círculos, o, para enfrente y para atrás. Según João (2011), rezar es un modo de crear el espacio social y el dominio de las parentelas. Dicho espacio social, en este caso, engloba personas, vegetales, animales y dueños (un conjunto de entidades invisibles que habitan y protegen el ambiente). Los cantos con mayor grado de complejidad, como son el largo canto ejecutado en los rituales de bautismo del maíz (avatykyry) y en el rito de pasaje kaiowa de los niños (kunumi pepy), eran

12 Recientemente hubo un declive de estas iglesias y las prácticas chamánicas que involucran los rituales han sido rescatadas y revaloradas. Asimismo, en 2004, tuve la oportunidad de participar de un ritual de nominación que acogió a pocas personas, realizado en una versión mínima, ocurrido en la casa del rezador.

13 De acuerdo con João (2011) y Pereira (2004), estos, conocidos como hexakáry, tenían la capacidad de comunicarse directamente con las divinidades, de viajar a niveles celestiales. Pasaban por un largo proceso de purificación corporal para retener la substancia de los cantos chamánicos en su cuerpo. Actualmente no hay alguien con esas características en la Tierra Indígena Caarapó, pero sí varios hombres y mujeres que son conocidos como ñanderu y ñandesy, con algún conocimiento de los rezos y relativo poder chamánico. 
entonados solamente por los chamanes más poderosos, pues exigen un dominio absoluto de las estrofas que lo componen.

Los cantos, en la concepción de los kaiowa, tienen sustancialidad, o sea, no son apenas memorizados, pero, conforme un aprendiz de rezador se va purificando, los cantos ocupan su cuerpo. De la misma forma, un canto se puede mantener por más o menos tiempo en el sitio en el que fue recitado (João, 2011), produciendo efectos perdurables. Existe una gran variedad de rezos que se usan para sacar entidades maléficas que viven en el entorno ambiental, para controlar los comportamientos considerados antisociales cuando hay muchas personas reunidas o para estimular el buen desarrollo de los cultivos y de las personas, entre otros. La fuerza de los cantos tiene el efecto de limpiar el espacio o proteger personas y siembras. Por otro lado, hay rezos que contaminan el espacio y provocan desgracias o enfermedades: estos son usados contra los enemigos.

Cuando los kaiowa y guaraní vivían en el monte, hace cuarenta o cincuenta años, el ciclo de vida era constituido, modelado y orientado por rezos y rituales que incluían también la agricultura. Schaden (1974) observó en esa región, en la década de 1950, que en torno a de la siembra de maíz se realizaban muchos procedimientos rituales. João (2011) indica que la práctica de los rituales con el canto largo, o jerosy puku, ocurrieron intensamente hasta la década de 1970. Una condición sine qua non para la realización de esos rituales es la producción de la bebida fermentada de maíz, kãgui ${ }^{14}$ o chicha, como resaltan los kaiowa y guaraní, incluso Cristina Barbosa en su testimonio. La descripción de los dos rituales que siguen, escrita a partir de los estudios de João (2011), Chamorro (1995), Vietta (2007), Pereira (2004), Montardo (2009) y Melià y otros (2008), pretende expresar cómo las prácticas chamánicas crean simultáneamente los espacios social y cosmológico.

El avatykyry o bautismo del maíz para la celebración de la cosecha tiene dos momentos: el rezo para las semillas (jehovasa) y el canto largo. Este ritual expresa la interrelación de las esferas social, económica y cosmológica de manera única. Es un evento que puede durar tres días o más: va a depender de cuánta chicha haya para ser consumida. Quien promueve el ritual es el llamado «dueño del maíz», el líder, que contribuye con la mayor parte de la chicha que será servida a los invitados, quienes pueden llegar de diversas aldeas. El canto largo abre el ritual en el atardecer

14 El kãgui era preparado solo por las jóvenes solteras, que masticaban el maíz previamente bautizado y cocido. Actualmente, la chicha todavía es bastante consumida en Te'ýikue, generalmente sin la etapa de masticación. Las mujeres apenas dejan una fluida papilla de maíz a fermentar naturalmente, después de ser cocida. 
del primer día y sigue hasta el amanecer. Las personas danzan todo el tiempo en círculo de un recipiente con chicha, junto con el chamán que entona el canto. Al amanecer, el chamán principal reza sobre la chicha y el ritual se detiene, hasta ser retomado al final de la tarde. Ese primer canto chamánico adquiere su fuerza con la chicha y al mismo tiempo la purifica, al impregnar la bebida con la sustancia de Jakaira, la divinidad kaiowa que crio el maíz. El segundo día incluye, además del canto largo, otro tipo de canto, el guahu, con el objetivo de alegrar a los participantes del ritual, lo que se repite en la noche siguiente. Una semana después, los participantes se reúnen nuevamente para realizar un canto corto que cierra el ritual.

El kunumi pepy es un ritual constituido por varias etapas en que los jóvenes kaiowa tenían sus labios perforados y adornados. El tembeta, adorno puntiagudo de resina usado entre la boca y la barbilla, es considerado símbolo del «legítimo kaiowa». Este ritual era realizado anualmente en el inicio de la temporada de frío, después del período del avatykyry. El ritual era anunciado meses antes para que todos los interesados pudieran participar. Incluía también la confección de un conjunto de objetos rituales y restaurar o construir la casa del rezado. Implicaba, por tanto, gran esfuerzo colectivo para recoger materias primas y trabajar para producir todo lo necesario, como adornos, indumentarias, instrumentos musicales y los bancos para sentar a los jóvenes y perforarles el labio. Además, incluye la preparación de mucha chicha y comida para los invitados. Los jóvenes solteros pasaban cerca de un mes confinados, hacían una dieta restricta y recibían enseñanzas sobre mitos y cantos. Después, se reunía a los demás participantes para realizar el canto largo, que era entonado solo por los chamanes, así como hacían en el ritual descrito en el bautismo del maíz. Entonces los jóvenes eran emborrachados con chicha para la colocación del tembeta, uno a uno, en medio de un clima de entusiasmo generalizado entre los hombres. Los rezos continuaban por algunos días más y después todos regresaban a sus casas.

La parte más solemne de estos rituales corresponde al jerosy puku, que es seguido de una fiesta propiamente dicha, con mucha danza, bebida y comida. João (2011) recuerda que la organización de esas fiestas ocupaba el centro de las atenciones en la aldea en que vivió cuando niño. También los esfuerzos conjuntos, los mutirões, realizados principalmente para abrir nuevas chagras y construir casas, involucraban el clima festivo y el consumo de chicha, aunque creo que con amplitud social menor que el de los rituales. Hoy en día, Panambizinho es uno de los raros lugares en el Brasil en que esos rituales son realizados con cierta regularidad por los kaiowa y guaraní. Vietta (2001) indica qué circunstancias histórico-contextuales posibilitaron que las parentelas que ya vivían en aquella 
área antes de la creación de la Colonia Agrícola de Dorados no se hayan desplazado y dividido tanto como en el caso de Caarapó.

El maíz blanco (avati morõti) es esencial para la realización de los rituales. Los kaiowa y guaraní poseen una buena variedad de maíces que son reproducidos por generaciones. Sin embargo, los cuidados con el maíz blanco son mayores, en el sentido de que garantizan todas las condiciones para que la planta se desarrolle. En términos de las técnicas agrícolas, de acuerdo con Pereira (2004), lo ideal es desmochar nuevamente, con el bosque bordeando la tierra para evitar que la planta, que tiene tallos largos y delgados, se tuerza por el viento. Este maíz blanco debe ser plantado lejos de otras variedades para evitar su cruzamiento.

Sin embargo, las técnicas agrícolas no pueden ser separadas de las prácticas chamánicas una vez que son los rezados frecuentes sobre los cultivos en crecimiento que los hacen florecer y madurar, de acuerdo con Melià y otros (2008). Además de enfatizar sobre los rezos, João (2011) destaca la importancia del ciclo lunar en el canto de los pájaros para la definición de los períodos de actividad agrícola en la tierra. Así, por ser «delicado» el cultivo de maíz blanco, no puede estar próximo de caminos o senderos muy frecuentados, carreteras u otras plantaciones.

El conjunto de cuidados necesarios para el sembrado del maíz blanco, que abarca la existencia del bosque y la responsabilidad implicada en promover las fiestas - esto es, tener la convicción de poder contar con la colaboración de un buen número de personas para llevar a cabo los rituales-, son factores que contribuyeron a que este maíz fuese cultivado cada vez menos entre los kaiowa y guaraní.

$\mathrm{Al}$ comentar sobre estos rituales, quiero llamar la atención sobre lo que destaca Pereira (2004): la producción económica y, por extensión, la producción de alimentos, se organiza a partir de fogones domésticos, pequeños grupos de personas que se consideran parientes próximos, y no se pauta por una reciprocidad generalizada. Desde una óptica económica, la relevancia de los rituales y fiestas motivadas por la producción agrícola es favorecer la solidaridad justamente en el círculo más extenso de las relaciones sociales entre las familias que integran las parentelas, como también entre parentelas distintas.

\section{LA DEGRADACIÓN AMBIENTAL, EL DECLIVE DE LAS FIESTAS Y LAS TRANSFORMACIONES EN LA ECONOMÍA KAIOWA Y GUARANÍ}

Los kaiowa y guaraní viven en las regiones de bosque de clima subtropical y de baja altitud (Melià, 1990). En Mato Grosso do Sul, ellos llegaron a ocupar un territorio que abarca la región situada entre el río Apa, la sierra de Maracajú, los 
ríos Brillante, Ivinhema, Paraná y Iguatemi, y la frontera con el Paraguay (Brand, 1997). Los kaiowa habitaban el espacio, de modo que una casa grande en que vivía una parentela, de preferencia en las proximidades de corrientes o ríos y rodeados de bosque denso, era circundada a cierta distancia por sus chagras, mantenidas en sistema de tumba y quema (Melià, 1990; Lehner, 2002). En el caso de los guaraní era semejante; sin embargo, la parentela se distribuía en un pequeño conjunto de casas. En el espacio de las chagras eran montadas las trampas de caza y las chagras antiguas servían también como lugar para recolectar frutas previamente plantadas (Pereira, 2004).

Lo que Brand (1997) define como proceso de confinamiento — la reunión forzada de grupos pertenecientes a parentelas distintas y, a veces, enemigas, en las reservas criadas por el SPI, sin posibilidad de circular por el territorio- tuvo como consecuencia la densidad poblacional y la inviabilidad de la manera de habitar el territorio descrita anteriormente. Con la tala de las áreas forestadas en Mato Grosso do Sul para la siembra de pastos o monocultivos, las actividades de caza, recolección y pesca dejaron de ser practicadas por los kaiowa y guaraní con la intensidad suficiente para proveer la alimentación diaria. Con la recuperación poblacional en las reservas indígenas, la propia agricultura quedó comprometida en las últimas décadas.

Según Brand (1997), el auge del confinamiento se dio en la década de 1980. Dos décadas después, la precarización de la vida de los kaiowa y guaraní alcanzó una evidencia perversa. En 2005, el hambre no puede ser más negligencia del Estado brasileño: en pocos meses diecisiete menores tuvieron como registro de causa de muerte la desnutrición severa, entre muchos menores originarios de varias aldeas que fueron tratados con grados menos severos de desnutrición y se recuperaron ${ }^{15}$. Este hecho tuvo enormes repercusiones en los ámbitos nacional e internacional, lo que provocó que el gobierno federal conformara una comisión interministerial para proponer acciones inmediatas. Desde esa época se mantiene la distribución sistemática de alimentos para las familias kaiowa y guaraní.

Es importante decir que los matorrales de las haciendas de ganado del entorno trajeron un problema adicional a las siembras en las Tierras Indígenas: la gran proliferación de pastos originarios de África. Actualmente, resulta difícil mantener una tierra sin el auxilio del tractor para arrancar los resistentes montones de brachiaria y otras poáceas (colonião) que crecen en áreas deforestadas y de

15 En la Tierra Indígena Caarapó, tuve oportunidad de visitar varias casas donde había menores desnutridos, juntamente con las agentes indígenas de salud. Algunas madres asociaban el cuadro de desnutrición a una enfermedad de la infancia conocida como kambyryru jere, que era tratada apenas por vencedores o rezadores (Silveira, 2009). 
rastrojos que requieren gran esfuerzo físico. Desde la década de 1970, el tractor viene siendo usado en la Tierra Indígena Caarapó para la abertura de huertos (Cariaga, 2011). Al principio, hubo incentivos de la FUNAI (Grünberg, 2002; Mura, 2005), que tenía como meta la producción de excedentes agrícolas entre las familias indígenas, particularmente de maíz, yuca y arroz. Hacerlos económicamente productivos era parte de la estrategia de integrar a los indios a la sociedad nacional (Thomaz de Almeida, 2001). Por lo tanto, además de organizar el trabajo de los hombres en la changa (como se llama al trabajo eventual fuera de la aldea), la FUNAI también procuraba adaptar su economía a los moldes occidentales y racionalizar el uso del espacio y la siembra, sin considerar, por ejemplo, las técnicas de consorcio que los kaiowa y guaraní utilizan en sus tierras.

Esos pastos que proliferan en las aldeas también están asociados a otros graves problemas, que son los incendios en las reservas. En la época de la sequía, entre los meses de mayo y julio, el pasto queda completamente seco e inflamable. Una colilla de cigarro encendida y tirada al suelo por descuido es capaz de iniciar un incendio difícil de controlar, como pude presenciar cierta vez. A veces, el fuego encendido para quemar la basura o para limpieza de un área de siembra se expande, alcanzando los pequeños espacios de bosque que todavía existen en la aldea.

Como ya mencioné, la presión poblacional consolidó la heterogeneidad social en la Tierra Indígena Caarapó. Así, solamente las parentelas con mayor prestigio político, cuyos líderes tienen más acceso a posiciones de trabajo fijo remunerado para sus parientes, consiguen canalizar suficientes recursos de organismos gubernamentales y no gubernamentales. Estas parentelas son también las que mejor consiguen organizarse para el trabajo en la changa (fuera de la aldea) a través del contratista, un hombre que hace de intermediario entre los trabajadores y los administradores que los contratan. La mayoría de los hombres que vive en esta aldea trabaja en las plantaciones de caña ${ }^{16}$, cultivadas en grandes latifundios para la producción de biocombustible. También hay los que trabajan diariamente en las haciendas de ganado. Un número reducido de mujeres, así como hombres, tiene trabajo fijo remunerado en la escuela y en el puesto de salud de la aldea. Otras mujeres se emplean en servicios domésticos remunerados y en la venta de ropas y cosméticos en el interior de la Tierra Indígena Caarapó.

16 Cuando comencé a visitar Te’ýikue, los trabajadores pasaban fuera poco más o menos de dos meses, principalmente entre mayo y noviembre, con intervalos de pocos días en la aldea. Uno de los problemas enfrentados debido a ese régimen de trabajo era que, cuando regresaban a la aldea, algunos hombres querían festejar y emborracharse e invariablemente ocurrían peleas. Por presión del Ministerio Público del Trabajo y otras instituciones, en 2008 el esquema cambió y las empresas pasaron a buscar y llevar diariamente a los trabajadores kaiowa y guaraní. 
Mapa 2. Tierra Indígena Caarapó
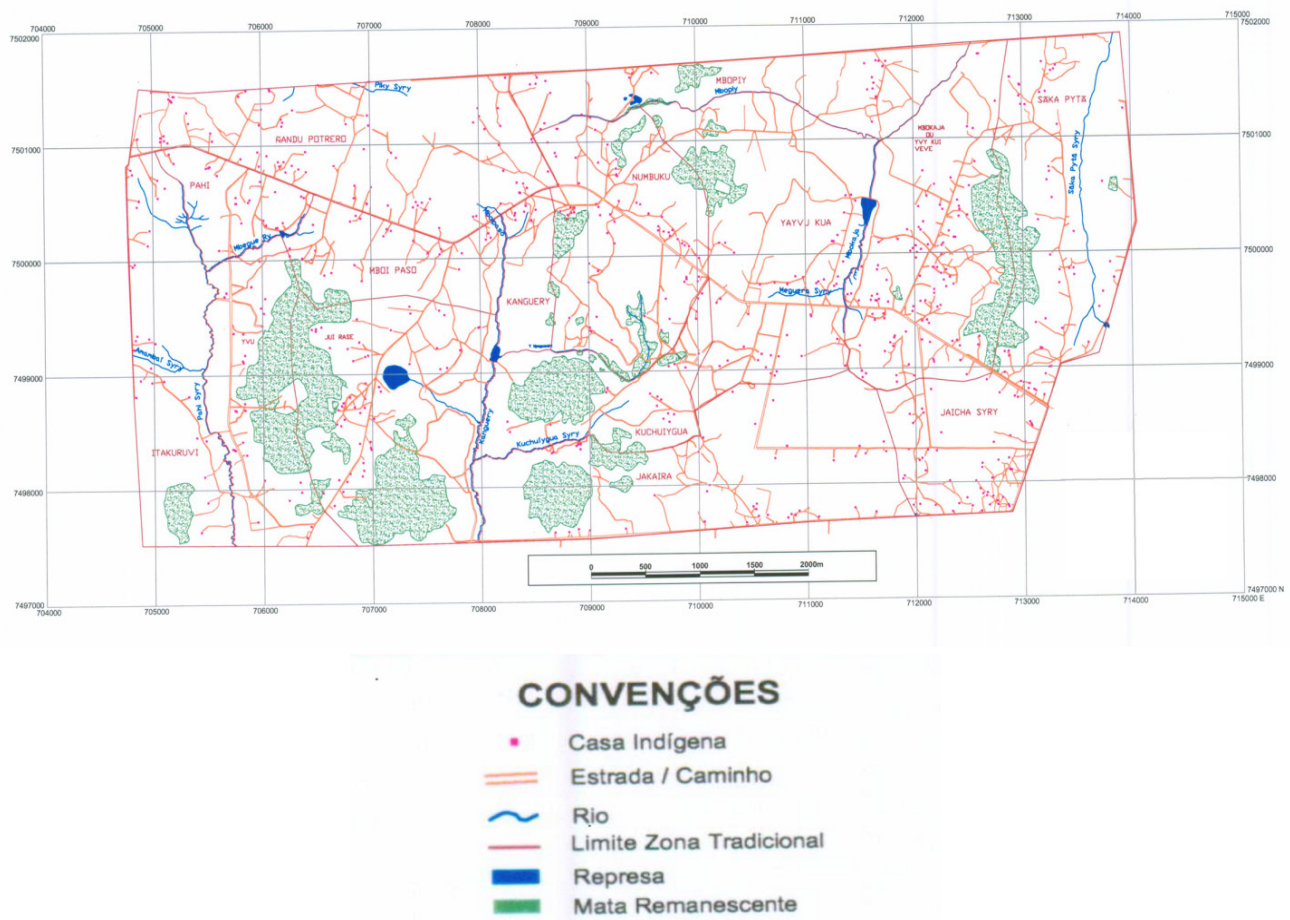

Fuente: Smaniotto, 2005/NEPPI-UCDB

Es preciso decir que, para mantener su prestigio político, los líderes necesitan mantener buenas relaciones con los agentes de diversos organismos municipales, estatales y otros con sede en la aldea, como las escuelas, el puesto de salud y el centro de referencia de asistencia social (CRAS), el vivero de plantas y las diversas iglesias que se han establecido en el lugar. Sin embargo, al precio es tener a los no indios influyendo cada vez más en su vida diaria, lo que en ciertas situaciones contribuye a debilitar la cohesión política entre los miembros de su propia parentela.

Desde una perspectiva más amplia, la alineación de la política de desarrollo en el Brasil a las tendencias del mercado mundial coincide con la intensificación de la deforestación en Mato Grosso do Sul, en las décadas de 1970 y 1980, cuando se consolidó también una nueva forma de articulación entre los representantes de agronegocios y el Estado brasileño, de acuerdo con Heredia, Palmeira y Leite (2010). A partir de entonces, la participación del capital internacional en el sector rural brasileño se viene intensificando. 
Además, el establecimiento de una bancada ruralista suprapartidaria en el Congreso Nacional después de la dictadura, para defender intereses de grandes propietarios y empresarios rurales (Vigna, 2001), impulsó inversiones del Estado en el sector, como también proyectos de enmienda constitucional para reducir los derechos de las poblaciones indígenas y tradicionales sobre sus territorios.

El agronegocio se mantiene en expansión en Mato Grosso do Sul (Casarotto, 2013; Brasil, 2013), con creciente tecnología involucrada en los procesos para aumentar su productividad y ganancias. Brasil se convirtió en uno de los líderes mundiales en la producción y exportación de etanol de caña de azúcar y del llamado complejo soya (óleo, salvado y grano), ambos con relevancia en la economía de este estado (Brasil, 2013). La producción de caña de azúcar aumentó vertiginosamente en la década pasada: de 99600 hectáreas en 2001 pasó a 399400 hectáreas en 2010. Por su parte, en 2010 la soya registró un área plantada de 1,7 millones de hectáreas, que rindió una recaudación de 5,3 millones de toneladas de granos (Casarotto, 2013). Además, el mayor rebaño bovino del país está en Mato Grosso do Sul (Silva, Silva, Ferrari y Lamparelli, 2010).

Se ve, de este modo, que el hambre entre los kaiowa y guaraní, relacionado con transformaciones en las dimensiones sociales, ambientales y económicas en el plano local, es correlacionada con cambios históricos que inviabilizan el acceso a los territorios tradicionales en favor de la monopolización e internacionalización de los recursos ambientales en Mato Grosso do Sul.

En el período crítico de los años 1980, los kaiowa y guaraní formaron el movimiento «Aty Guasu» para enfrentar la presión de los propietarios rurales, sea en el cotidiano de la aldea, sea en el ámbito más regionalizado, con el propósito de reconquistar sus territorios tradicionales (ver Benites, 2014). En estas asambleas, que ocurren regularmente, participan kaiowa y guaraní de todo el estado. Ahí son alternados rezos encabezados por chamanes prestigiados, conversaciones solo entre ellos, y momentos de debate y reivindicación junto a agentes de diversos órganos de gobierno.

Ellos cuentan también con aliados actuantes en el escenario regional: el Consejo Indigenista Misionario (CIMI), organización ligada a la Iglesia católica, y el proyecto Kaiowa Nandeva, organización no gubernamental. Ambas entidades apoyan los enfrentamientos de los kaiowa y guaraní desde la década de 1970. Hay también varias entidades con actuación puntual en determinadas tierras indígenas, como el NEPPI-UCDB. En la esfera del Estado, el Ministerio Público Federal viene trabajando insistentemente en pro de los derechos indígenas en Mato Grosso do 
$\mathrm{Sul}^{17}$. La FUNAI ha asumido una posición ambivalente. A pesar de una reestructuración reciente en las directrices de la política indigenista teniendo como base la Constitución Federal, ese organismo no tiene autonomía política y tampoco los recursos adecuados para implementar las políticas públicas que se hacen necesarias.

\section{INSEGURIDAD ALIMENTARIA Y POLÍTICAS PÚBLICAS}

En aproximadamente cien visitas domiciliarias que hicimos entre 2006 y 2007 entrevistando a las mujeres, verificamos que la gran mayoría de ellas subsistía con sus hijos de las canastas de alimentos ${ }^{18} \mathrm{y}$ del salario que sus esposos recibían en la changa. No fue posible analizar hasta qué punto los alimentos y recursos eran redistribuidos en las parentelas. Nuestra tentativa de aplicar un cuestionario de frecuencia alimentaria se frustró en la medida en que la respuesta más recurrente de estas mujeres era «cuando tengo, como». Los esposos tienen un número variable de hijos, difícilmente menos de cuatro, aunque pueden llegar a diez, doce o más hijos, sin contar los otros parientes incorporados al fogón doméstico. La canasta de alimentos que recibían estaba compuesta de arroz, frijoles, aceite, azúcar, harina de maíz, leche en polvo y macarrones, en cantidades que no aseguraban ni siquiera la comida para dos semanas. El salario era usado en parte para la compra de alimentos, pero también para todas las necesidades de ropa, materiales escolares, artículos de higiene, etcétera.

En fin, constatamos que varias mujeres pasaban algunos días del mes sin tener alimentos para comer u ofrecer a sus hijos. Esto las dejaba exasperadas, pues enfatizaron que siempre es necesario tener comida preparada para los niños pequeños, ya que ellas comen todo el tiempo en el día. Sin embargo, en esa época, el pesaje de los niños menores de cinco años de edad se realizaba de forma rigurosa por la FUNASA ${ }^{19}$, como todavía hoy, y aquellos evaluados como

17 Además, de los kaiowa y guarani, viven en Mato Grosso do Sul los terena, ofaié, guató, kadiweu, kinikinau, atikum y kamba. Los terena forman una gran población, así como los kaiowa y guaraní, representando respectivamente cerca de $1,17 \%$ y $1,77 \%$ de la población del estado, según datos del IBGE del censo de 2010. Los terena también enfrentan fuertes conflictos por la tierra en función de la pérdida de buena parte de sus territorios tradicionales.

18 Coimbra y otros (2013), al relatar resultados preliminares de la Encuesta Nacional de Salud y Nutrición de los Pueblos Indígenas, afirman que en la región centro-oeste las canastas de alimentos tenían el más alto porcentaje como método de obtención de alimentos entre todas las regiones del país. En esa región fue también donde se registraron las aldeas más pobladas.

19 La Fundación Nacional de Salud actuó en la salud indígena hasta 2010, cuando se creó una Secretaría Especial de Salud Indígena (SESAI) vinculada directamente con el Ministerio de 
desnutridos eran luego tratados y acompañados. Así, y a pesar de la inseguridad alimentaria, había pocos casos de desnutrición infantil y ningún caso en grado severo en aquel período.

La niñez en edad escolar disponía de dos comedores en la escuela. Había cuatro unidades escolares en la aldea de la Terra Indígena Caarapó. Al dialogar con sus cocineras, todas mujeres kaiowa o guaraní, comprobamos que la comida siempre se preparaba al estilo de los blancos. Algunas cocineras declararon que, cuando hacían comida tradicional, los menores poco la aceptaban. Ese dato es relevante, pues examinando relatos recogidos en diferentes circunstancias, notamos cierta controversia entre el uso de maíz y de leche de vaca (o soya) en la alimentación infantil. Los abuelos criticaban el uso de la leche, decían que antiguamente los niños eran engordados con chicha de maíz y no estaban enfermos como ahora. Las agentes indígenas de salud recomendaban a las madres que ofrecieran la leche como parte de las orientaciones dadas por los profesionales de salud para tratar la desnutrición infantil. En la escuela los niños tenían, con frecuencia, leche achocolatada o café con leche en la merienda. Ese antagonismo entre lo tradicional y las innovaciones alimentarias corresponde a una dinámica social que implica cambios en los estilos de comportamiento de las parentelas, con grados diversos de proximidad con el estilo de los no indios, según discuten Cariaga (2011) y Pereira (2010).

En otras reservas indígenas donde viven los kaiowa y guaraní, Galvão (1996) registró, en la década de 1940, una intensa ocurrencia de trabajo colectivo para producir chagras, seguido por fiestas con mucha chicha. Aunque en ese momento muchos hombres trabajaban en la changa, este énfasis del autor nos hace pensar que el ciclo económico que ordenaba la vida social y el consumo de alimentos se basaba en el intercambio de productos de las chagras entre las familias.

En la Tierra Indígena Caarapó, en los años 2000 quedó patente el hecho de que la estacionalidad alimentaria ya no está vinculada con el calendario económico de los propios kaiowa y guaraní, pero sí con los ciclos de trabajo en la changa. Esto puede ser una característica indicativa de la ausencia de soberanía alimentaria, acorde con Marques (2010), porque los circuitos locales de producción y consumo de alimentos dejaron de ser controlados por las parentelas kaiowa y guaraní.

la Salud, con la finalidad de optimizar la transferencia de recursos para acciones en salud indígena del sistema público de salud. 
Cuando fue realizado este estudio, el programa Bolsa Familia ${ }^{20}$ no tenía la cobertura que alcanzó entre los pueblos indígenas en la década siguiente, de modo que los ingresos y la circulación de dinero entre los miembros de las parentelas tenían como fuente principal, para la mayoría de la población de la aldea, la changa. Me inclino a creer que, posteriormente, la renta mensual del Bolsa Familia pasó a representar una diferencia significativa para la disponibilidad de alimentos en aquellas familias en condiciones más desfavorables en la Tierra Indígena Caarapó.

En la aldea, lo que más se veía en las chagras eran yuca, papa-dulce, arroz del seco, frijol, maíz híbrido, piña y caña de azúcar. La mayoría de las parejas criaba algún tipo de ave, comúnmente gallinas y patos. También se criaban cerdos, bueyes y vacas, sin embargo, menos que las aves. Lo mismo ocurría entre los fogones domésticos que conseguían tener un pedazo tierra razonable para cultivar, pues era imposible mantenerse mayoritariamente de la producción agrícola.

Las preparaciones culinarias tanto kaiowa como guaraní no presentan diferencias sustanciales; por el contrario, muestran mucha convergencia de características en lo que es considerada la comida típica. Sin embargo, hay marcadores alimenticios que las diferencian. Las larvas (mbuku) que se crían en troncos de palmera son, todavía, bastante consumidas entre los guaraní. Los kaiowa gustaban de comer termitas y algunos tipos de hormigas, mas no larvas, por eso identifican a los guaraní como aquellos que comen larvas. Por su parte, los guaraní se refieren a los kaiowa como comedores de un tipo de lagarto (teju), carne que ellos no aprecian.

Percibimos que, en las parentelas más estructuradas — quiero decir, las que poseían una pareja o uno de los cónyuges todavía vivo y que conseguían sumar al menos dos generaciones a su alrededor, con prestigio político suficiente para garantizar el ingreso regular de recursos - estaban las familias que todavía consumían los alimentos tradicionales en alguna medida. Entre estos, fueron bastante citados: chicha, xipa (pan de maíz asado o cocido), hu'i (harina hecha de yuca, trigo o maíz tostado con aceite), jopara (arroz y frijol cocido juntos); locro (maíz en sopa con carne de res o pollo); puchero (carne con hueso en sopa y yuca), y yuca y papa-dulce asadas o cocidas en el fuego colocado en el suelo. A pesar de la mínima disponibilidad, alguna caza y pescado también eran consumidos. En

20 Es un programa de transferencia directa de renta del gobierno federal que tiene como meta retirar familias de la situación de extrema pobreza en que se encuentran. Forma parte del Plano Brasil Sin Miseria, que tiene por objetivo a todos los brasileños con una renta familiar inferior de R\$ 77 mensuales. Ver http://www.mds.gov.br/bolsafamilia 
estos casos, los parientes con trabajo fijo, regular, o todavía en retiro, colaboraban más con los alimentos industrializados.

Los kaiowa y guaraní que representan la generación de los abuelos y bisabuelos prefieren artículos o ingredientes que definen su comida tradicional siempre que pueden, pues no se acostumbran a la comida de los no indios. Ellos continúan preparando los alimentos al estilo guaraní, esto es, asados en las brasas del fuego o cocidos, con poco o ningún sazonador o especias. Son los más viejos, en general, quienes poseen las mejores plantaciones, incluyen no solo la chagra, sino también una especie de huerto y algunos remedios caseros en el patio de la casa.

Evaluamos que las peores situaciones se daban en los casos de familias que no estaban asociadas con una parentela de prestigio o se encontraban en posición marginal en una parentela. La niñez y juventud que crecen sin las relaciones cercanas con sus abuelos y bisabuelos no aprenden a apreciar la cultura alimenticia tradicional. Se notaron todavía casos recientes de separación de parejas matrimoniadas en donde el esposo dejaba de colaborar en la economía familiar. Son situaciones en que la red de intercambios es más limitada. En estos casos hay una dependencia mayor a las políticas gubernamentales, como la merienda escolar y la canasta de alimentos. Se observó, en fin, un cuadro de inseguridad alimentaria persistente en la Tierra Indígena Caarapó, que, como sabemos, es una situación que se presenta en otros asentamientos habitados por los kaiowa y guaraní en el Brasil.

Desde la perspectiva de los propios kaiowa y guaraní, es en los rituales en torno del maíz en que los rezos, danzados, entonados y proyectados en el espacio, generan las condiciones climáticas, sociales y cosmológicas para la abundancia en las chagras, como también de animales para caza y pesca, donde se produce la disponibilidad de alimentos con calidad y cantidad suficientes para alimentar a todos. En el pasado, en la época anual de la escasez de cultivos, alrededor del mes de octubre, ellos utilizaban una gama de alimentos alternativos que encontraban en el bosque (Müller, 1989). Esta estrategia se volvió inviable luego de la destrucción ambiental.

Dentro de las políticas de seguridad alimentaria y nutricional que alcanzan efectivamente a los kaiowa y guaraní de la Tierra Indígena de Caarapó, se destacan la Acción de Distribución de Alimentos, el Programa Nacional de Alimentación Escolar y el Programa Bolsa Familia. Además, a pesar de haber sido implementada la oferta de las canastas de alimentos como una acción de emergencia, esta ha sido la manera prioritaria encontrada por el Estado para enfrentar a inseguridad alimentaria entre los pueblos indígenas hace mucho tiempo. 
Nótese que todas las acciones citadas implican poner a disposición productos alimenticios o dinero para comprar alimentos comercializados en la ciudad, sin incentivo a la economía local o a la producción alimentaria en la aldea. De modo que no cabe en esas políticas la soberanía alimentaria, quiero decir, la definición, por los propios kaiowa y guaraní, de las estrategias de producción y distribución sostenible de alimentos (Conti, 2009). Su autonomía se restringe a decidir consumir o no lo que les es ofrecido en las canastas de alimentos, como también, decidir comprar comida u otros artículos con el dinero que reciben del gobierno a través de la Bolsa Familia.

\section{CONSIDERACIONES FINALES}

A lo largo de este texto he pretendido mostrar que, entre los kaiowa y guaraní, el conjunto de los rituales y fiestas que garantizan su seguridad alimentaria, asociado a los recursos del bosque y a una vida social plena en su territorio, se inviabilizó en menos de cinco décadas. La escasez generalizada de las fiestas motivadas por la siembra de alimentos tal vez sea el cambio más dañino para su modo de vida. Por haber escuchado tantos relatos de hombres y mujeres más ancianos que vivieron eso, me parece que en los días actuales no existe un movimiento aglutinador, en el interior de las aldeas y entre ellas, tan expresivo como el que era producido en los rituales que articulaban la producción de alimentos a los ciclos sociales y cosmológicos entre los kaiowa y guaraní. En ese sentido, el hambre en las aldeas puede ser entendido como un índice de discontinuidad de un régimen de relaciones originados en la interacción con el paisaje ambiental, ligado a los rituales en torno de la agricultura.

Aunque las políticas públicas para enfrentar una situación persistente de inseguridad alimentaria están en curso, las acciones más efectivas en Te'ýikue se orientan a poner a disposición recursos para adquisición de alimentos o alimentos procesados para consumo. Se enfocan fundamentalmente en el acceso a los alimentos. A pesar que la distribución de canastas de alimentos fue formulada como acción de emergencia, la FUNAI, como órgano articulador de la política indigenista, no ha conseguido avanzar ni proponer e implementar acciones alternativas en materia de seguridad alimentaria. En este punto de vista, no se trata apenas de estimular la economía de subsistencia para que se realice la soberanía alimentaria: la cuestión es garantizar que las políticas de seguridad alimentaria y nutricional promuevan la autodeterminación de estos pueblos. Se podría trazar un camino desde la política de gestión territorial y ambiental de las tierras indígenas, 
que aún es incipiente, pero antes, es inevitable cuestionarse la explotación de los recursos ambientales y de las tierras en esta región del Brasil.

De ese modo, se evidencia que el principio de soberanía alimentaria, de la forma como fue incorporado a la LOSAN para orientar las políticas de seguridad alimentaria y nutricional en el Brasil, no da cuenta de la especificidad de los pueblos indígenas. En el modelo económico neoliberal, la decisión sobre la producción y el consumo de alimentos a escala nacional no es suficiente para garantizar condiciones que aseguren la producción local de los alimentos en términos de la diversidad sociocultural y de todas las dimensiones del vivir de estas poblaciones en las cuales las prácticas para la producción alimentaria están entrelazadas.

Mencioné antes que las élites rurales y las inversiones transnacionales consolidaron el agronegocio en Mato Grosso do Sul, en detrimento de la garantía de los territorios indígenas. Sin embargo, el papel del Estado en ese proceso no puede ser menospreciado, porque hay políticas públicas en la base de todos los cambios que dieron lugar al agronegocio, como enfatizan Heredia y otros (2010). Primero, llegaron políticas relativas al reordenamiento territorial y la organización del trabajo indígena para el desarrollo regional. Hay, todavía, decisiones de aplicar o no políticas ambientales, dependiendo de cada situación y de los intereses en juego ${ }^{21}$. Por otro lado, las políticas de crédito, financiamiento y renegociación de deudas de estos productores rurales han implicado una fuerte inversión estatal, según los mismos autores. Y, especialmente en la última década, se observa la preocupación, en el gobierno federal, con inversiones en infraestructura para el flujo de producción.

Una de las cuestiones fundamentales a ser evaluada, tomando en cuenta el contexto político actual y el foco en el desarrollo económico, es la necesidad de una reserva de tierra disponible para la expansión de los agronegocios en lugares donde hay inversión internacional (Chonchol, 2005). Aquí se muestra, por un lado, que entre las consecuencias del neoliberalismo para los kaiowa y guaraní

21 Las ventas anuales de agrotóxicos en el Brasil, entre 2000 y 2010, tuvieron un crecimiento de $136,7 \%$, posicionándolo como el segundo país con el mayor mercado consumidor en el mundo. Mato Grosso do Sul es uno de los estados que destaca en esa estadística. Los riesgos de contaminación ambiental, intoxicación de trabajadores y de contaminación de alimentos son directamente proporcionales a la intensificación del uso y el grado de peligrosidad de los productos utilizados (Brasil, 2013). No es raro escuchar quejas de los kaiowa y guaraní sobre los efectos de las pulverizaciones realizadas por avionetas en las plantaciones que rodean sus tierras: estas les producen efectos como dolor de cabeza, dolor de barriga y vómitos en los niños. 
están los cambios en la movilidad y usos del territorio, así como en las esferas política, chamánica y en la vida social misma, que convergieron en el desuso de sus rituales y fiestas. Por otro lado, se percibe que las recientes negociaciones, referencias y avances para modificar los procedimientos de regularización de tierras para los pueblos indígenas y tradicionales en los poderes federales indican la preferencia del Estado brasileño por continuar garantizando la expansión de los agronegocios.

\section{REFERENCIAS}

Barbosa da Silva, Alexandra (2012). Relatório Circunstanciado de Identificação e Delimitação da Terra Indigena Iguatemipeguá. Brasília: FUNAI.

Benites, Eliel y Rosa Colman (2012). A educação escolar indígena na aldeia Te 'ýikue. Caderno de resumos do IV Seminário Internacional Fronteiras Étnico-culturais e Fronteiras da Exclusão. Campo Grande: UCDB, 1, 1-15.

Benites, Tonico (2014). Rojerokyhina ha roikejevytekohape (Rezando e lutando): o movimento histórico dos Aty Guasu dos Ava Kaiowa e dos Ava Guarani pela recuperação de seus tekoha. Tese (Doutorado em Antropologia Social). Rio de Janeiro: UFRJ/MN.

Brand, Antonio J. (1997). O impacto da perda da terra sobre a tradição Kaiowál Guarani: os dificeis caminhos da palavra. Tese (Doutorado em História). Porto Alegre: PUC/RS.

Brand, Antonio J. (2010). Impasses no Processo de Demarcação de Áreas Indígenas. Palestra em Mesa-Redonda no $\mathrm{XI}^{\circ}$ Encontro Nacional da $6^{\circ}$ Câmara de Coordenação e Revisão - Ministério Público Federal. Campo Grande [mimeo]

Brasil (2013). Relatório de Qualidade do Meio Ambiente. RQMA: Brasil 2013, Brasília: IBAMA Recuperado de http://www.ibama.gov.br/phocadownload/rqma/ RQMA_2013.pdf Consultado en 15 abril 2014.

Cariaga, Diogenes E. (2011). As transformações no modo de ser criança entre os Kaiowá em Te'ýikue (1950-2009). Dissertação (Mestrado em História). Dourados: UFGD.

Casarotto, Eduardo L. (2013). Desempenho da pauta de exportações do agronegócio de Mato Grosso do Sul. Dissertação (Mestrado em Agronegócios). Dourados: UFGD.

Cavalcante, Tiago. (2013) Colonialismo, território e territorialidade: a luta pela terra dos Guarani e Kaiowa em Mato Grosso do Sul. Tese (Doutorado em História e Sociedade). Assi: UNESP. https://doi.org/10.4025/6cih.pphuem.244 
Chamorro, Graciela (1995). Kurusu Ñe’ëngatu. Palabras que la historia no podría olvidar. Asunción: Ceaduc/São Leopoldo: IEPG-Comín.

Chonchol, Jacques (2005). A soberania alimentar. Estudos Avançados, 19(55), 33-48. https://doi.org/10.1590/S0103-40142005000300003

Coimbra Jr., Carlos E. et alli (2013). The First National Survey of Indigenous People's Health and Nutrition in Brazil: rationale, methodology, and overview of results. BMC Public Health. https://doi.org/10.1186/1471-2458-13-52

Conti, Irio L. (2009). Segurança Alimentar e Nutricional: noções básicas. Passo Fundo: IFIBE.

Fausto, Carlos y Michael Heckenberger (2007). Indigenous History and the History of the «Indians». In C. Fausto, M. Heckenberger (orgs.), Time and memory in indigenous Amazonia: anthropological perspectives (pp. 1-43). Gainesville, FL: University of Florida Press.

Fundación Nacional del Indio (FUNAI) (2012). Quadro Demonstrativo da Situação Fundiária atual dos Guarani e Kaiowa em Mato Grosso do Sul. Nota técnica $\mathrm{n}^{\circ} 16$, Brasília.

Galvão, Eduardo (1996). Diários Kaioá (1943). In Marcos A. Gonçalves (org.), Diários de Campo de Eduardo Galvão - Tenetehara, Kaioá e Indios do Xingu (pp. 175-247). Rio de Janeiro: UFRJ.

Grünberg, Friedl P. (2002). Reflexões sobre a situação dos guarani no Mato Grosso do Sul, Brasil. URL: http://www.guarani.roguata.com/articles/index.php?language=spa Consultado en 10 mai 2006.

Heredia, Beatriz, Marcos Palmeira y Sergio P. Leite (2010). Sociedade e economia do «agronegocio» no Brasil. Revista Brasileira de Ciências Sociais, 25(74), 159-196. https://doi.org/10.1590/S0102-69092010000300010

João, Izaque (2011). Jakaira reko nheypyru marangatu mborahéi: origem e fundamentos do canto ritual jerosy puku entre os Kaiowa de Panambi, Panambizinho e Sucuri'y, Mato Grosso do Sul. Dissertação (Mestrado em História). Dourados: UFGD.

Lehner, Beate (2002). Territorialidad guaraní. Ensayo sobre la relación territorio organización sociopolítica de los Ava-Guarani y Pai-Tavyterã. Recuperado de http://www.guarani.roguata.com/articles/index.php?language=spa Consultado en 10 mayo 2006.

Lima, Marcos H. F. y Verônica M. B. Guimarães (2013). Clean biofuels and the Guarani Indians of Mato Grosso do Sul: human costs and violation of rights. Comunicação apresentada no $17^{\circ}$ IUAES, Painel Survival and Extintion, Manchester. 
Marques, Paulo Eduardo Moruzzi (2010) Embates em torno da segurança e soberania alimentar: estudo de perspectivas concorrentes. Revista Segurança Alimentar e Nutricional, 16(2), 78-87. https://doi.org/10.20396/san.v17i2.8634795

Melià, Bartomeu (1990). La tierra sin mal de los guaraní. Economía y profecía. Revista de Antropología, 33, 33-46.

Melià, Bartomeu, Georg Grünberg y Friedl P.Grünberg (2008 [1976]). Paĩ-Tavyterã. Etnografia guarani del Paraguay contemporáneo. Asunción: CEADUCCEPAG.

Montardo, Deise L. (2009). Através do mbaraka: música, dança e xamanismo guarani. São Paulo: Edusp.

Müller, Franz (1989 [1934]). Etnografia de los Guarani del Alto Parana. Rosario: Societatis Verbi Divini.

Mura, Fabio (2005). Por que fracassam os projetos de desenvolvimento entre os Guarani de Mato Grosso do Sul? Notas críticas para uma política de sustentabilidade. Tellus, 8/9, 53-72.

Noelli, Francisco S. (1999). Curt Nimuendajú e Alfred Métraux: a invenção da busca da «terra sem mal». Suplemento Antropologico, 34(2),123-166.

Pereira, Levi M. (2004). Imagens Kaiowá do sistema social e seu entorno. Tese (Doutorado em Antropologia Social). São Paulo: USP.

Pereira, Levi M. (2007). Mobilidade e processos de territorialização entre os Kaiowá atuais. História em Reflexão, 1(1), 1-33 URL:http://www.periodicos.ufgd.edu. br/index.php/historiaemreflexao/issue/view/17/showToc Consultado en 20 jun 2013.

Pereira, Levi M. (2010). A socialização da criança kaiowá e guarani: formas de socialidade internas às comunidades e transformações históricas recentes no ambiente de vida. Comunicação, Anais $34^{\circ}$ Encontro Anual da ANPOCS [Caxambu].

Schaden, Egon (1974). Aspectos Fundamentais da Cultura Guarani. São Paulo: Edusp.

Silva, Ariadiny M. da, João S. V. da Silva, Diego L. Ferrari, Rubens A. C. Lamparelli (2010). Vegetação natural e área antrópica em Mato Grosso do Sul até o ano de 2002. Comunicação, Anais $3^{\circ}$ Simpósio de Geotecnologias no Pantanal. Cáceres.

Silveira, Nádia H. (2009). Mitã kambyryru jere - notas sobre uma doença de infância entre os Kaiowá e Guarani. Tellus, 16, 209-214.

Silveira, Nádia H. (2016). Discriminação, impasses sociais em Mato Grosso do Sul e o bem-viver kaiowa e guarani. In E. J. Langdon, M. Grisotti (org.), Políticas públicas: reflexões antropológicas (pp. 211-227). Florianópolis: Editora da UFSC. 
Thomaz de Almeida, Rubem (2001). Do desenvolvimento comunitário a mobilização política: o Projeto Kaiowa-Ñandeva como experiência antropológica. Rio de Janeiro: Contra Capa.

Thomaz de Almeida, Rubem y Fabio Mura (2004). Historia y territorio entre los Guaraní de Mato Grosso do Sul. Revista de Indias, 64(230), 55-66. https://doi. org/10.3989/revindias.2004.i230.410

Vietta, Katya (2001). Tekoha e te'yguasu: algumas considerações sobre articulações políticas Kaiowa e Guarani a partir das noções de parentesco e ocupação espacial. Tellus, 1, 89-102

Vietta, Katya (2003). «Pastor dá conselho bom»: missões evangélicas e igrejas neopentecostais entre os Kaiowa e Guarani em Mato Grosso do Sul. Tellus, 4, 109-135.

Vietta, Katya (2007). Histórias sobre terras e xamãs kaiowa: territorialidade e organização social na perspectiva dos Kaiowa de Panambizinho (Dourados, MS) após 170 anos de exploração e povoamento não indígena da faixa de fronteira entre $o$ Brasil e o Paraguai. Tese (Doutorado em Antropologia Social). São Paulo: USP.

Vigna, Edélcio (2001). Bancada ruralista: um grupo de interesse. Argumento $\mathrm{n}^{\mathrm{o}} 8$ INESC. Brasília URL: http://www.inesc.org.br/biblioteca/textos/bancada-ruralista-um-grupo-de-interesse/view Consultado en 20 jun 2013.

Xavier, Leonardo P. (2018). Soberania alimentar: proposta da via campesina para o sistema agroalimentar. Brazilian Journal of Development, 4(7), Edição Especial, 4454-4466. 